\title{
La flor de mi secreto: El deseo de la creación en Pedro Almodóvar
}

\author{
Doralba Pérez Ibáñez \\ Institución Universitaria Colombo Americana-ÚNICA \\ d.perez@unica.edu.co
}

\begin{abstract}
The Flower of My Secret (1995) stands out as one of the least cited films in Pedro Almodóvar's filmography. This absence of critical attention contrasts with the care that the director put into the construction of its characters and the consideration he paid to each of the details that made up this melodrama. The flower of my secret keeps many of Almodóvar's usual traits, but with a particular tone that makes this film a defining moment in his career, since it marks a transition in his creative process, it constitutes a before and an after in his filmic production.

In this essay I analyze the trope of creation in The Flower of My Secret and explain the reasons why this film could be considered Almodóvar's most metafictional work, since it reflects on each of the elements that are part of his creative universe. The film is an eulogy to the process of both literary and cinematographic creation in the format of a melodrama; the viewer travels,
\end{abstract}


in 103 minutes, across the tropes that constitute the Almodovarian universe, either explicitly or through allusion. The film pays tribute to its name.

Keywords: Almodóvar; The Flower of My Secret; Metafiction and film; Tropes; autobiography

\section{Resumen}

Entre la filmografía de Pedro Almodóvar La flor de mi secreto es una de las películas menos citadas. Este olvido resulta injusto dado el cuidado que el director manchego puso en la construcción de los personajes de la misma y a la atención prestada a cada uno de los detalles que componen este excelente melodrama. Realizada en 1995, La flor de mi secreto guarda muchas de las características habituales de Almodóvar, pero con un tono particular que hacen de este film un momento definitorio en su carrera, ya que, marca una transición en su proceso creador. Por lo tanto, la película es una pausa en la cual, con paciencia de relojero, el director toma una a una las piezas que hacen marchar su máquina de sueños y obsesiones, las pule, las reorganiza y las hace andar con dirección a lo que será su nueva perspectiva.

La película es en sí un elogio al proceso de creación tanto literario como cinematográfico en el formato de un melodrama; razón por la cual el espectador recorre, en 103 minutos, los tropos que constituyen el universo almodovariano ya sea de manera explícita o a través de la alusión. La película hace homenaje a su nombre y a través de ella se devela la flor del secreto de todos y cada uno de los fetiches estéticos del director, es el antes, el durante y el después. En este corto análisis que propongo pretendo analizar el tropo de la creación en $L a$ flor de mi secreto y como esta película podría ser considerada, por excelencia, la obra más metaficcional de Almodóvar, por cuanto reflexiona en cada uno de los elementos que hacen parte de su universo creativo.

Palabras clave: metaficción; autobiografía; La flor de mi secreto; Pedro Almodóvar; tropos 
a flor de mi secreto (1995) encierra muchas de las características del cine de Almodóvar, pero posee un tono particular que hace de este filme un momento definitorio en su carrera, ya que marca una transición en su proceso creador. La película es una pausa en la cual, con paciencia de relojero, el director toma una a una las piezas que hacen marchar su máquina de sueños y obsesiones, las pule, las reorganiza y las hace andar en dirección a lo que será su nueva perspectiva. El filme es en sí un elogio al proceso de creación tanto literario como cinematográfico en el formato de un melodrama; razón por la cual el espectador recorre, en 103 minutos, los tropos que constituyen el universo almodovariano, ya sea de manera explícita o a través de la alusión. La película hace homenaje a su nombre y a través de ella se devela la flor del secreto de todos y cada uno de los fetiches estéticos del director; es el antes, el durante y el después de su filmografía.

En este estudio exploro el tropo de la creación en La flor de mi secreto y cómo esta película podría ser considerada, por excelencia, la obra más metaficcional de Almodóvar, por cuanto reflexiona acerca de cada uno de los elementos que forman parte de su universo creativo, en especial la cinematografía y la escritura. 25 años después de su lanzamiento se hace más clara la relevancia de esta obra en la carrera del director, pues en ella se condensan muchas de las claves para comprender los derroteros de lo que ha sido hasta ahora su obra.

Los procesos autoreflexivos, también denominados metaficcionales, especulares o narcisistas, han sido materia de estudio para diversos autores. Por ejemplo, para Carmen Bustillo (202) los procesos metaficcionales consisten en la inclusión de la ficción dentro de la ficción misma del texto, un mise en abyme en la cual el texto se desdobla en su propio comentario crítico proporcionando claves para su desciframiento. Por su parte, Linda Hutcheon (1980) explica la narrativa narcisista como una ficción que habla de sí misma a la vez que incluye dentro de sí un comentario acerca de su propia identidad narrativa o lingüística. Al mismo tiempo, la metaficción, según Carrera (2001) 
se centra en "su propia categoría de artificios para plantear la problemática correspondencia entre ficción y realidad" (33). La película de Almodóvar que analizo en este ensayo se constituye en una metaficción de la obra del director, en cuanto de principio a fin se explica la construcción de su universo fílmico, reflexiona sobre ella y esboza entre líneas sus orígenes y su futuro.

En La flor de mi secreto, Marisa Paredes, una de las actrices fetiche de Pedro Almodóvar, encarna, en una actuación desgarradora, a Leo Macías, una escritora en crisis. Leo ha publicado, con gran éxito comercial, una larga serie de novelas rosas bajo el seudónimo de Amanda Gris. Sin embargo, Leo está harta de la vida y de ser Amanda Gris y por esta razón ha cambiado su tono. Su última historia ha sido rechazada por la editorial que publica sus obras porque de escritora de novela rosa Leo se ha transmutado en escritora de novela negra. La vida de Leo es como un barco sin timón que flota a la deriva perdida en un océano de conflictos amorosos, familiares y profesionales que debe afrontar para alcanzar, por fin, la estabilidad y paz mental anheladas.

La película se inicia con una dramatización en la que dos médicos hablan con la madre de un paciente que sufrió muerte cerebral, le están comunicando la noticia para solicitarle la donación de los órganos del joven. Luego el plano de la cámara se abre y vemos a un camarógrafo que está filmando la escena mientras Betty, la mejor amiga de Leo, la observa a través de la pantalla de un televisor, a la vez, nosotros como espectadores vemos el panorama completo a través del lente de la cámara que lo filmó.

Esta suerte de juego de cámaras y espectadores al mejor estilo de una "Matrioshka" o "muñeca rusa" es el escenario perfecto para un juego voyerista en el cual actores, espectadores y director se encuentran atrapados. En primer lugar, los personajes interpretan el papel de actores que fingen ser personajes reales-dos médicos y una enfermera-y que dentro de la escena pretenden encarnar la vida de otras personas-doctores hablando con la madre de un paciente informándole que su hijo sufrió muerte cerebral a causa de un 
accidente de motocicleta.

Estos personajes se observan entre sí mientras actúan; la cámara los toma por separado en planos medios y primer plano, guiando la mirada del espectador hacia cada uno de los interlocutores según hablan. Mientras esto sucede, repentinamente vemos la imagen del camarógrafo que filma la escena, recordándonos que lo que acabamos de ver es una dramatización, una película dentro de la película. Los actores son observados por el lente de una cámara que proyecta sus imágenes a un televisor a través del cual son observados por nosotros los espectadores de la película, por la audiencia reunida en el salón y por Betty, quien se encuentra al lado del televisor. Repentinamente nuestra mirada se encuentra con la de Betty y por unos segundos los espectadores somos capturados en el juego de realidades y proyecciones de este complejo engranaje metaficcional. Llegados a este punto, es importante hacer notar que cuando Betty nos mira está usando anteojos, lo cual hace que su mirada no sea directa, sino que también se produzca a través de un lente. Si bien es cierto que la utilización de un escenario de grabación es un tropo frecuente en Almodóvar, es en esta película donde este segmento de la filmación cumple con el papel central de servir de metáfora absoluta de la propuesta estética de la misma.' Esta secuencia es la metáfora central de toda la película y cumple varias funciones: la primera es servir de alegoría del momento de crisis en el que se encuentra Leo, su matrimonio ha muerto y ella no acepta esta realidad, nadie ha sido capaz de darle la mala noticia de su pérdida, ni siquiera Betty, su mejor amiga, encargada de organizar estos seminarios para médicos por ser una experta en dar malas noticias. La vida emocional de Leo se tambalea, su esposo Paco-Imanol Arias-es un soldado que participa, desde Bruselas, en una misión de paz en la guerra de Bosnia. Paco se muestra cada vez más ocupado y distante, no atiende a sus llamadas ni intenta devolverlas. Leo no puede vivir sin él y se encuentra perdida en todos los aspectos de su vida, incluido el literario. Su fragilidad es evidente, siente que el amor de su marido 
se le escapa de las manos y no sabe cómo manejar la situación. En el tablero que se encuentra en la sala del simulacro la cámara muestra los diferentes sentimientos que experimenta la persona que se enfrenta a una pérdida; sentimientos que Leo experimentará uno a uno a lo largo del filme: "Pena, rabia, dolor, impotencia, alivio, soledad, vacío, frustración e injusticia." El tablero es enfocado allí, adrede como una especie de comentario al margen acerca de lo que como espectadores vamos a ver a continuación, este hecho es implícitamente, un acto narcisista.

Como explica Hutcheon (1980), la metaficción es una ficción que incluye en sí misma un comentario acerca de su propia identidad narrativa o lingüística; las escenas iniciales de La flor de mi secreto son en sí una reflexión con anotaciones al margen de lo que será la película como un todo, lo cual las hace narcisistas en el sentido de referirse a textos autoconscientes de su condición original universal. El título de la novela inacabada de Amanda Gris (seudónimo de Leo) En frío también nos remite a la misma metáfora de mujer muerta en vida, al igual que Manuela, la madre que acaba de perder a su hijo, y que no encuentra consuelo alguno en su diálogo con los doctores del hospital:

Dr. Fernando: Estas cosas ocurren todos los días.

Manuela: ¿Todos los días? ¡A mí no se me muere un hijo todos los días, oiga! (02:24)

Leo tampoco encuentra consuelo al dolor que le produce la muerte de su relación conyugal:

Leo: Como siga bebiendo así, acabaré convirtiéndome en una alcohólica anónima (...) Ay, Betty, excepto beber, qué difícil se me hace todo. (15:00) Betty: Leo, no eres la única mujer que tiene problemas con su marido Leo: ¡Eso no es ningún consuelo! (15:39) 
El hijo de Manuela da la impresión de estar vivo porque lo sostienen las máquinas de asistencia hospitalaria, pero en realidad está muerto, y esa realidad sólo se hace evidente en la conversación con los médicos. La relación de Leo y su esposo da la impresión de estar viva por las vagas y escasas interacciones que ambos sostienen, su esposo aún no le ha hecho el comunicado oficial de ruptura, por eso, Leo sigue aferrada a la idea de que dicha relación sigue viva. Ambas circunstancias producen un inmenso dolor en los seres afectados. El sentimiento del dolor causado por el distanciamiento de un ser querido y el dolor que produce la muerte de un hijo son considerados en la misma categoría. Al respecto Almodóvar explica que:

La flor de mi secreto es un filme sobre el dolor. Un dolor de proporciones casi épicas. Pero no es una película épica sobre el dolor. El dolor es el del abandono y creo que ese tipo de sufrimiento se siente de verdad como un duelo físicamente. Poco importa que la persona que se ha ido siga viviendo para el resto del mundo, el final de la relación equivale a una muerte. (citado en Strauss 140)

La segunda función de esta secuencia de la muerte cerebral es develar el secreto de la historia que se desarrollará cuatro años más tarde en otro exitoso filme de Almodóvar: Todo sobre mi madre (1999). En éste, Manuela, una enfermera con el mismo nombre y oficio de la mujer que asiste a Betty en los videos del Plan Nacional de Donación de Órganos, debe recibir la mala noticia de la muerte cerebral de su hijo y firmar la documentación para autorizar el trasplante de sus órganos. Marsha Kinder analiza La flor de mi secreto como la primera parte de una trilogía de películas de Almodóvar dedicadas al tema de la muerte cerebral, y analiza las películas Hable con ella (2002), Todo sobre mi madre y La flor de mi secreto, como una metáfora de la reinvención de la patria española tras la dictadura franquista. Para Kinder La flor de mi secreto "nos muestra cómo se pueden recuperar diversas imágenes de España y de sus 
recursos más tradicionales como si se tratase de órganos vitales antes de ser trasplantados al siglo XXI" (9).

Esta sugestiva escena del Plan Nacional de Donación de Órganos se conecta con la imagen de una ventana de persianas cerradas que se abren lentamente para dejarnos ver dese el interior de una habitación, una imagen reveladora que refleja el pasado y el presente del Madrid de los 90s. Al lado derecho vemos un edificio de arquitectura contemporánea y al lado izquierdo una construcción con claros rasgos de arquitectura mudéjar. Esta fascinación por el contraste arquitectónico que devela el paso del tiempo, la apreciamos también en la primera escena de Laberinto de pasiones (1982) y en Mujeres al borde de un ataque de nervios (1988). Vemos también la torre de una iglesia, tropo recurrente en otras películas de Almodóvar como Entre tinieblas (1983), que transcurre en un convento, y Matador (1986), dónde la madre del protagonista es una beata rezandera y en La ley del deseo (1987), cuándo Tina, la hermana transgénero del protagonista, confiesa que su primer amor cuando era chico fue un sacerdote y va a la iglesia a visitarlo, aspecto que más tarde se repite en La mala educación (2004). Curiosamente en esta misma secuencia de La ley del deseo la cámara enfoca en un plano picado el patio de una escuela lleno de niños jugando, escena que veremos años más tarde en La mala educación.

Este retorno del director a su locus habitual y la proyección del locus futuro están enteramente ligados a la característica metaficcional de la película, ya que la metaficcionalidad va de la mano de la auto-representación y los comportamientos de referencia auto-textual porque realiza una mirada sobre sí misma y sobre sus procesos, su desarrollo y su capacidad de gestar nuevas ideas. En esta secuencia, por un lado, la cámara de Almodóvar realiza un recorrido narcisista por los lugares comunes del universo fílmico del director, acaricia estos espacios, casi con nostalgia lleva al espectador a los lugares visitados en sus producciones anteriores y a la vez los pone en frente de los lugares que visitará en sus nuevas películas. Por otra parte, en esta escena, el 
director nos posa sobre el sitio estratégico desde el cual podemos tener acceso a la vista de la ciudad, la ventana, símbolo voyerista por excelencia; la cámara nos hace notar que estamos en la habitación de Leo, su espacio más íntimo. Ella está dormida, con una pasividad que recuerda la de los muertos, Leo está muerta en vida, la cámara nos guía para que fisgoneemos en sus objetos personales, su mesa de noche, fotos, libros, su escritorio, espacio de creación por excelencia, y sus apuntes. Esta escena es familiar, ya la hemos vivido en La ley del deseo y Mujeres al borde de un ataque de nervios, con la diferencia de que, como en la escena del hospital analizada anteriormente, cuando la mirada de Betty sorprende a los espectadores espiando, esta vez es el viento el que interrumpe bruscamente la intromisión del espectador. Repentinamente la ventana se abre por culpa de un viento fuerte que alborota las páginas de un libro, entonces, escuchamos la voz de Leo que dice: "indefensa frente al acecho de la locura." $Y$ el sonido de una máquina de escribir en la que vemos que Leo escribe sin cesar la misma línea, como estancada en su proceso creador. El texto corresponde a la novela de Juan José Millás Ella imagina (2010): "Indefenso frente al acecho de la locura, pues de eso me salvaba fundamentalmente la rigidez de las costumbres; de la locura con la que llevo pactando desde que tengo uso de razón" (89). Esta frase podría encerrar dos significados. Por un lado, el estado de desasosiego en el cual se encuentra Leo, la escritora de novelas rosas que ahora sólo puede escribir novelas negras. Por otro lado, la cita puede conectar con el estado de creación del director mismo, quien, como Amanda Gris, se debate en su proceso creador sobre el rumbo de sus próximas producciones, sus secretos que se ven revelados en esta película y la rigidez de sus costumbres, sus tropos comunes. El título de la obra de Millás que se escoge para la secuencia, Ella imagina, nos hace saber que ese estado de muerte en vida en el que se encuentra Leo, también puede ser interpretado como el estado de imaginación in situ del artista. Para Marvin D’Lugo lo que vemos en La flor de mi secreto es "una versión de la pugna entre dos versiones 
de la realidad, una rosa y otra negra" (90); la novela negra representa una violación del contrato de Amanda Gris, en el que se estipula que sus obras deben contener:

Tomás: Leo te contratamos para que escribieras historias de amor... novelas de amor y lujo en escenarios cosmopolitas, sexo sugerente y sólo sugerido, deportes de invierno, sol radiante, urbanizaciones, subsecretarios, ministros, yuppies.... Nada de política, ausencia de conciencia social.... Hijos legítimos, los que quieras, eso sí... final feliz. (35:03)

Esta pugna interna es la misma a la que se enfrenta el director, tras el aclamado éxito de Mujeres al borde de un ataque de nervios, ya que, sus películas posteriores_Átame (1990) y Kika (1993) - fueron apedreadas por la crítica debido a su contenido sórdido. Esta clave de dicotomías se mantiene en cada aspecto de la obra y, así, la película lidia con dos realidades posibles, representando el conflicto entre las historias rosas que Amanda Gris debe escribir por exigencia de sus editores y las historias negras que fluyen de su pluma creadora influida por su estado emocional, como se observa en el siguiente diálogo:

Alicia: Leo, lo que nos has mandado no es una novela de Amanda Gris. ¿A qué viene este cambio?

Leo: Supongo que estoy evolucionando.

Alicia: ¿Por qué?

Leo: Tal vez porque estoy viva.

Alicia: No, quiero decir ¿Por qué cambias si las ventas no bajan? Leo bonita, olvidas que nuestra colección se llama Amor Verdadero. ¿Cómo se te ocurre venirnos con una historia de una madre que descubre que su hija ha matado a su padre después de que éste intentara violarla; ¿y que para que nadie se entere, la madre lo hiberna en la cámara frigorífica del restaurante de un vecino? (32:50) 
A través de este diálogo, el director nos revela un secreto importante, la novela que Leo entregó a sus editores, titulada La cámara frigorífica, contiene el argumento de uno de los más grandes éxitos cinematográficos de Almodóvar, la película Volver (2006). Este diálogo también sirve para poner de manifiesto la crisis que produce en el sujeto creador la falta de libertad creativa y como esta libertad se ve coartada por la mercantilización del arte. El artista se ve sujeto a cumplir con la demanda del público y no con sus propios intereses; es así como, el arte se produce en masa, como en una fábrica y se pierde la individualidad que caracteriza al arte y la libertad del artista de tomar sus propias decisiones. Al inicio de la escena en la cual se produce este diálogo, Alicia le informa a Leo que acaban de imprimir la segunda edición del más reciente libro de Amanda Gris, mientras la cámara enfoca grandes pilas de copias del libro cargadas por una máquina y por obreros. Bajo estos parámetros mercantilistas, al artista no se le permite cambiar o evolucionar, Leo atribuye el cambio en sus creaciones al hecho de estar viva, y por ende a la conexión con la realidad, incluso explica que parte del argumento está basado en hechos reales ocurridos en Puerto Rico y, sin embargo, Alicia desprecia esta situación:

¡La realidad! ¡Bastante realidad tenemos cada una en nuestra casa! La realidad es para los periódicos y la televisión... Y mira el resultado. Por culpa de ver y leer tanta realidad el país está a punto de explotar. ¡La realidad debería estar prohibida! (32:04)

El acto opresor que ejerce Alicia al querer atar a Leo a las normas del contrato, en cierto modo, significa prohibirle vivir, es mantenerla en un estado de muerte en vida, una especie de muerte cerebral en la cual las máquinas de la industria editorial son las que controlan el cerebro del artista y sus producciones. Leo, como se lo expresa a Alicia, su editora, no sabe escribir novela rosa, le sale negra, lo intenta, pero cada página le sale más negra, se encuentra agotada y deprimida y su estado emocional se hace evidente en su obra. Ella no puede 
más con la idea de ser Amanda Gris y no apuesta por el tipo de literatura que produce, como se lo hace saber a Ángel, el director de El País, cuando éste le encarga escribir un editorial donde critique la obra de Amanda Gris: “No creo que la literatura sentimental se ocupe lo más mínimo de los sentimientos. No hay dolor, ni desgarro. Sólo rutina, complacencia y sensiblería (...). Me temo que no soy la persona más adecuada... Me horroriza Amanda Gris..." (La flor de mi secreto). Por su parte, Ángel secretamente se muere de ganas por ser una escritora de novelas rosa como Amanda Gris, en lugar de dedicarse a redactar noticias. ${ }^{2}$ Este tipo de reflexiones en la película, en las cuales se abordan los dilemas que enfrentan los escritores acerca de su relación con el proceso creador constituyen un claro ejemplo de metaficción, ya que, como lo explica Patricia Waugh, "metaficción" es un término para designar la escritura ficticia que llama la atención de manera consciente y sistemática a su condición de arteficio para plantear cuestiones sobre la relación entre la ficción y la realidad (40). En otras palabras, las obras metaficcionales son aquellas que exploran una teoría de la escritura de ficción a través de la práctica de escribir ficción, es por esto que, los espectadores de La flor de mi secreto observan, como invitados de primera fila, el proceso de creación en el instante en el cual se produce.

En este proceso de creación in situ, el espectador tiene además el privilegio de presenciar cómo los personajes se van construyendo dentro de la película misma, se puede observar cómo luchan por definirse a medida que la trama se desarrolla, ver como ellos navegan en un mar de incertidumbres, dudas y mentiras que los conducen finalmente a un desenlace. Por ejemplo, Leo es Amanda Gris y se debate como ya lo hemos analizado entre la vida y la muerte, entre el rosa y el negro, entre la pasión prohibida que le despierta Antonio, el joven bailarín de flamenco, hijo de su asistenta y el sosiego que le ofrece una posible relación con el dulce Ángel, el hombre que a diferencia de Paco su esposo, está hecho a su imagen y semejanza. Ángel es su alter ego por excelencia. 
Por su parte, Paco es un militar valiente capaz de pelear en una guerra extranjera, pero a la vez es un pobre cobarde que no se atreve a confesarle a su esposa que ya no la ama y que tiene una amante, tiene miedo de enfrentarse a la guerra que le espera en casa. Por otro lado, Betty es una psicóloga experta en dar malas noticias, pero no es capaz de decirle a Leo que su relación con Paco ha llegado a su fin. A la vez lucha entre ser la mejor amiga de Leo o su antagonista sentimental, la mujer que le ha robado el amor de su esposo. Otro caso de indecisión y miedo que se presenta en la película es el de Blanca, quien es la empleada doméstica de Leo durante el día y durante la noche es una bailarina de flamenco, doble vida que también le causa conflictos internos. Por otra parte, Antonio es un bailarín de flamenco muy dotado que para lograr ejercer su arte es capaz de hacer lo que sea, robar, engañar e incluso prostituirse con hombres o con mujeres. Él representa en sí mismo la otra salida sórdida que le queda al artista que quiere ejercer su arte. A la vez, interpreta el papel de ese personaje constante en la filmografía de Almodóvar: el joven guapo de sexualidad fluctuante que comercia con su cuerpo para lograr lo que quiere. ${ }^{3}$ Así, se pone de manifiesto, nuevamente, el conflicto del artista y su capacidad de libre creador, aspecto que ya Almodóvar había abordado en la película dentro de la película que se presenta en Laberinto de pasiones, y que abordará más tarde en Los abrazos rotos (2009), en donde el productor de "Chicas y maletas" abusa de su poder y manipula la cinta para convertirla en un bodrio y así vengarse de Mateo Blanco, el libretista y director.

Un segundo tropo que Ilena el personaje de Antonio es el de las relaciones incestuosas, las cuales se presentan de manera explícita en Laberinto de pasiones, La ley del deseo, Volver y Kika, y se sugieren en Tacones lejanos, cinta de 1994. Este tipo de relaciones dejan de ser explícitas en esta película y se subliman en la danza erótica entre Antonio y Blanca, su madre. Esta danza también fluctúa entre dos mundos, entre el flamenco tradicional, que no lo es y la danza contemporánea, que tampoco llega a serlo. 
En este ir y venir de personajes en construcción, Leo se destruye a pedazos, tras una corta visita conyugal en la que Paco le confirma el final de su matrimonio, ella decide acabar con su vida tomándose un frasco de calmantes. Esta acción inicia una de las escenas más cargadas de simbología de todo el filme, la muerte y el renacimiento de Leo.

Leo yace en la cama, aparentemente muerta, cuando de repente suena el teléfono, la llamada pasa al contestador automático y se escucha la voz de Jacinta, la madre de Leo, pronunciando su nombre y anunciándole que ha decidido regresar al pueblo. La cámara se aleja y enfoca el pasillo oscuro, dando la apariencia de un túnel, y de repente Leo vuelve a la vida, en medio de un ataque de vómito. En la siguiente toma Leo se encuentra sumergida en la bañera y sale abruptamente del agua mientras se escucha un fuerte grito que forma parte de la siguiente escena en la cual transmiten por televisión un concurso de gritos. En la escena siguiente se ve a Leo caminando como una muerta en vida, como en estado de zombi por en medio de una gran manifestación de estudiantes de medicina protestando por el colapso del servicio médico español. En medio de la marcha Leo se choca con Ángel y se desmaya en sus brazos. Esa noche, bajo la influencia del alcohol le confiesa a Ángel su más íntimo secreto:

Leo: Seguro que ayer bebí y hablé demasiado.

Ángel: Sí, y entre otras cosas, me descubriste "la flor de tu secreto," como diría Amanda Gris. (1:06:24)

Esta confesión parece servir como un acto de escisión entre Leo y Amanda Gris y desde ese momento Amanda pasa de habitar el cuerpo y la mente de Leo a cohabitar el cuerpo y la mente de Ángel, quien de ahora en adelante producirá las obras de Amanda Gris. En la transmutación de Ángel, parece cumplirse el precepto de Welles quien afirma que la ficción nos permite ser maestros de nuestro propio destino transformando la realidad y creando una nueva más a 
nuestro gusto o en palabras de Agrado, uno de los personajes más recordados del filme Todo sobre mi madre: "Una es más auténtica cuanto más se parece a lo que ha soñado de sí misma."

Sin embargo, deshacerse de su otro yo no es suficiente para curar a Leo. Su estado emocional oscila entre el dolor por la pérdida de la estabilidad sentimental y la aventura y el cambio que representa abrazar la vida como se presente; la sensación de enfrentarse a estos caminos produce angustia, desolación y miedo, sentimientos que la hacen dudar de su propio estado mental:

Leo: Me estoy volviendo loca, mamá.

Jacinta: ¿Tú? Esa es tu hermana, pero tú, no.

Leo: Sí. Como las tías, como su abuela. Loca.

Jacinta: Es por Paco, ¿verdad? Me lo estaba figurando, me lo estaba figurando.

Ay, qué pena, hija mía. Tan joven y ya estás como vaca sin cencerro.

Leo: ¿Como vaca sin cencerro?

Jacinta: Sí; perdida, sin rumbo, sin orientación. Como yo. (1:17:07)

La solución para reestablecer la coherencia y el orden de las ideas, para recuperar el rumbo y la orientación, se encuentra en regresar a los orígenes, al inicio de la historia personal y desde allí recuperar las fuerzas necesarias para volver a comenzar, para sobreponerse a las confusiones e incluso reinventarse, por esta razón, Leo regresa en compañía de su madre al pueblo.

Jacinta: Yo también estoy como vaca sin cencerro. Pero a mi edad, es, es más normal. Por eso quiero vivir aquí en el pueblo. Cuando a las mujeres nos deja el marido, porque se ha muerto, o se ha ido con otra -que, para el caso, es igual-, nosotras debemos volver al lugar donde nacimos. Visitar la ermita del santo; tomar el fresco con las vecinas, rezar las novenas con ellas; aunque no seas creyente. Porque si no, nos perdemos por ahí como vacas sin cencerro. (1:17:43) 
El retorno al pueblo o a la aldea ya sea para buscar los orígenes, recuperar la historia, confrontar los fantasmas del pasado, o construir una nueva identidad a partir de esta visita, es un tropo recurrente en la filmografía de Almodóvar; aparece en ¿Qué he hecho yo para merecer esto? (1984), La ley del deseo, Átame y Volver, por mencionar algunas. Esta necesidad de volver al origen se replicará también en Dolor y gloria (2019), ya no a través del desplazamiento físico, sino a través de la memoria del protagonista y de su obra cinematográfica.

Para Leo, el pueblo es una tabla de salvación, es el lugar donde se recupera la fuerza perdida y donde se reorganiza la vida, es también el lugar donde se busca la felicidad. Además de visitar el pueblo, en el filme se revisitan también muchos motivos populares como la música, los tejidos, el flamenco y los tablados, la paella, la decoración mudéjar y la tradición oral, ejemplo de esta última es el poema que recita la madre en el coche y los cantos de las comadres del pueblo.

Santos Zunzunegui (1999) destaca la divulgación de motivos populares de la cultura española que hace el director manchego:

[Almodóvar] es un ejemplar revisitador de innumerables formas estéticas de la tradición española, desde el folletín o la novela sentimental hasta el cuplé, pasando, claro está, por el bolero (...) cuya función no se limita a ilustrar sus filmes, sino que, en bastantes casos, sirve de modelo (como espectáculo melodramático completo en sí mismo, como obrita autosuficiente) para determinadas interpolaciones tan habituales en su cine. (122)

Considero que este revisitar los lugares comunes en sus obras forma parte, en general, del proceso de autorreflexión y autoconciencia creadora de Almodóvar. Y en particular, en La flor de mi secreto, es más una manera de 
abrir los cajones de la mente para hacer un inventario de lo que se tiene, qué uso se le ha dado y qué modificaciones se deben hacer para que el engranaje de la gran máquina creadora que es El Deseo, S.A. siga adelante con éxito. Una muestra de esta organización de tropos es por ejemplo la figura del travesti, tan presente en varios de sus filmes, en éste sólo se les hace un guiño al mostrarlos en el sótano del teatro en el que se presentan Antonio y Blanca. La ubicación de los mismos, el sótano, parece indicar su arraigo dentro de la producción fílmica total de Almodóvar. Los veremos salir nuevamente a la luz en Todo sobre mi madre y en La mala educación y caminar sonrientes por la calle en Julieta (2016).

En este filme se observa más que nunca el interés por establecer los derroteros de lo que será el futuro de la carrera fílmica del director manchego, volviendo a la metáfora inicial del trasplante de órganos; es en esta película donde parecen tomarse las decisiones acerca de qué elementos trasplantar a las futuras producciones almodovarianas.

Por una parte, se nos ofrece el guion de dos nuevas películas (Volver y Todo sobre mi madre) y se nos muestra una escena simbólica que se retomará en La mala educación, película que, junto con La ley del deseo y Dolor y gloria, completará la trilogía de cintas protagonizadas por directores de cine que tienen como temas centrales el deseo y la ficción cinematográfica. Por otra parte, se enfatiza la importancia que la literatura, las producciones fílmicas fetichizadas por el director y la música tienen en el cine Almodóvar. En este análisis autoconsciente, se sacan al sol, una a una las prendas del armario, se revelan el deseo y las pasiones de Almodóvar; en otras palabras, se brinda la oportunidad única al espectador de explorar y conocer mejor la flor de su secreto. 


\section{Notas}

1 Recordemos el inicio de La ley del deseo (1987), ¿Qué he hecho yo para merecer esto? (1984) O el contexto de: Pepi, Luci, Bom y otras chicas del montón (1980), Laberinto de pasiones (1982), Átame (1990), Tacones lejanos (1991), Kika (1993), La mala educación (2004), Hable con ella (2002), Volver (2006), Los abrazos rotos (2009); por mencionar algunas en que todas estas cintas o bien se está filmando una película o bien se está trabajando en la televisión.

2 En la escena en la que Leo llama a Ángel para preguntarle si él es el responsable de las dos novelas de Amanda Gris que la editorial acaba de recibir, Ángel lleva puesta una camiseta con la imagen de Patty Diphusa, alter ego de Almodóvar en sus años de juventud.

3 Toni en Pepi, Luci, Bom y otras chicas del montón, Sadec en Laberinto de pasiones, Miguel en ¿Qué he hecho yo para merecer esto?, Antonio en La ley del deseo, o Juan en La mala educación.

\section{Obras citadas}

Bustillo, Carmen. La aventura metaficcional. Equinoccio Ediciones de la Universidad Simón Bolívar, 1998.

Carrera, Liduvina. La metaficción virtual. Universidad Católica Andrés Bello, 2001.

D’Lugo, Marvin. "Genealogía de las 'sórdidas comedias neosurrealistas' almodovarianas." Almodóvar: El cine como pasión: Actas del Congreso Internacional "Pedro Almodóvar," Cuenca, 26 a 29 de noviembre de 2003, edited by Fran A. Zurián and Carmen Vázquez Varela, Universidad de Castilla La Mancha, 2005, pp. 81-91.

La flor de mi secreto. Directed by Pedro Almodóvar, performances by Marisa Paredes, Juan Echanove, Carmen Elías, Rossy de Palma, Chus Lampreave, Kiti Manver and Alberto Iglesias, Culver City, Sony Pictures Home Entertainment, 2005.

Hutcheon, Linda. Narcissistic Narrative: The Metafictional Paradox. Wilfrid Laurier UP, 1980.

Kinder, Marsha. "Reinventing the Motherland: Almodóvar's Brain-Dead Trilogy." Film Quarterly, vol. 58, no. 2, 2004, pp. 9-25. 
Millas, Juan José. Ella imagina y otras obsesiones de Vicente Holagado. Penguin Random House Grupo Editorial España, 2010.

Strauss, Frédéric. Conversaciones con Pedro Almodóvar. Ediciones Akal, 2001.

Todo sobre mi madre. Directed by Pedro Almodóvar, performances by Cecilia Roth, Marisa Paredes, Penélope Cruz, Candela Peña, Juan A. San, Rosa M. Sardà, Gómez F. Fernán, Fernando Guillén and Toni Cantó, Culver City, Sony Pictures Classics, 2007.

Waugh, Patricia. "What is Metafiction and Why are They Saying Such Awful Things About it?” Metafiction, edited by Mark Currie, Longman, 1995, pp. 39-54.

Welles, Marcia L. "Carmen Martín Gaite: Fiction as Desire." From Fiction to Metafiction: Essays in Honor of Carmen Martín Gaite, edited by Mirella Servodidio and Marcia L. Welles, The Society of Spanish and Spanish-American Studies, 1983, pp. 197-207.

Zunzunegui, Santos. El extraño viaje: El celuloide atrapado por la cola o la crítica norteamericana ante el cine español. Episteme, 1999. 